\title{
Numerical back-analysis of simulated rockburst field tests by using coupled numerical technique
}

\author{
P. Zhang Luleå University of Technology, Sweden \\ C.P. Yi Luleå University of Technology, Sweden \\ E. Nordlund Luleå University of Technology, Sweden \\ S. Shirzadegan Luleå University of Technology, Sweden \\ U. Nyberg Luleå University of Technology, Sweden \\ L. Malmgren Luossavaara-Kiirunavaara $A B$, Sweden \\ A. Nordqvist Luossavaara-Kiirunavaara $A B$, Sweden
}

\begin{abstract}
In order to assess the capacity of ground support systems when submitted to dynamic loading, simulated rockburst tests utilising blasting have been performed for many years in different countries with limited success. In general, the blasts need to be carefully designed in order to reach the goal; however, different blast layouts, e.g. blasthole angle, burden, have been used based on researcher's experience without conducting detailed analyses, the exception being a field test by CSIR. Recently, field trials have been conducted at the LKAB Kiirunavaara underground mine with some unexpected results which show that either the whole tested panel was destroyed or only a few fractures were formed without any ejections being observed. The aim of this paper is to investigate the failure mechanism in the simulated rockburst tests and improve the blast design by back-analysing the test results using a coupled numerical modelling technique. The blast was simulated by using finite element method (LS-DYNA) and the dynamic interaction between the blasting generated waves and the opening was simulated by using discrete element modelling (UDEC) with the dynamic input from LS-DYNA. The numerical modelling showed that blasting can create both radial fractures radiating from the blasthole and fractures parallel or subparallel to the surface of the tested panel caused by reflected tensile stress waves. By comparing the results of the numerical modelling with the measured data, it is shown that the collapse failure was mainly controlled by the creation of a cone-shaped area formed by radial fractures and the burden seems to be a critical factor. In order to obtain fractures caused by reflected tensile stress waves and reduce blasting induced radial fractures, two parallel blastholes are suggested with larger burden $(>5 \mathrm{~m})$ for future tests. Furthermore, the limitation of the current numerical modelling has also been discussed. The coupled numerical technique has shown its advantage when simulating blasting as well as interaction between waves and opening and it can thus be used as a tool for extrapolating results from simulated rockburst experiments if detailed geological structure and ground support systems can be incorporated in the model and the model can be well calibrated.
\end{abstract}

\section{Introduction}

In the second half of 2007 and the beginning of 2008 a number of seismically induced large rockfalls occurred in the Kiirunavaara underground iron ore mine. On 2 February 2008, a large seismically induced rockfall event caused a fatality. The mine has since then been regarded as seismically active, after it had experienced several larger seismically induced rockfalls. A number of different actions have been taken in order to manage the new rock mechanical conditions at the mine. One of them is to evaluate the performance of different support systems and develop a new rock support system for dynamic loads as the traditional rock support design at Kiirunavaara underground mine has been based on only experience and local rock conditions under static loading situation (Dahner et al., 2012). 
In order to assess the performance of ground support components and systems when subjected to seismic activity and strong ground motion, laboratory tests on core, drop test facilities, simulated rockburst experiments, and passive monitoring and back-analysis for case studies have been employed for many years in different countries (Hadjigeorgiou and Potvin, 2007). According to a philosophical view on the testing of rock support for rockbust conditions (Stacey, 2012), it is concluded that it is impossible to design support systems under rockburst condition by using a conventional approach, since neither the demand on a support system nor the capacity of a support system can be satisfactorily defined. Therefore, to obtain necessary safety for severe conditions the design of the rock support cannot only be based on simplified analyses, but it should preferably be proven by field tests. One way is to test the rock support system, in interaction with the rock, by simulated rockburst experiments using blasts as a source of dynamic loads.

Using explosive charges in an attempt to simulate the effects of rockbursts on ground support systems is not a new concept. Until now, there is no standard on how to conduct simulated rockburst experiments and different blast designs have been utilised in existing simulated rockburst experiments (Ortlepp, 1992; Tannant et al., 1995; Hagan et al., 2001; Espley et al., 2004; Archibald et al., 2004; Andrieux et al., 2005; Heal and Potvin, 2007). A major concern on designing simulated rockburst experiments is how to minimise the effects of gases. Note that within the context of this work 'gas effects' will refer to the venting of hot pressurised detonation gases through the burden. It must, however, be remembered that the detonation gases do contribute to the total vibrational loading of the rock, even if no venting occurs locally (Andrieux et al., 2005). Among different blast designs, results from an angled blasthole layout have shown relatively poor simulation due to difficulties in controlling gases and explosive quantity, while results from parallel blasthole layout with larger burden $(>5 \mathrm{~m}$ ) have instead shown relatively good simulation (Hadjigeorgiou and Potvin, 2007). Three consecutive blasts with parallel blastholes were used by the University of Western Australia (UWA) to generate three levels of vibrations for each tested support system. It could be argued that in the second and third blast, the rock mass had already been fractured due to first (and second) blast, therefore, it is very hard to state that gas effects have been separated from shock wave. In addition, in order to reach higher ppv on the surface for damaging support, larger quantities of explosives have to be used when the burden is larger, which is neither practical nor economical. There is no clear conclusion regarding the balance between burden and reasonable amount of explosive at different tested situations. As a result, trials have to be conducted in order to find a standard blast design which can be further used to investigate different support systems. During 2010-2012, a series of underground experiments with one parallel blasthole were conducted at the Kiirunavaara underground iron ore mine. It was surprising that very high ppvs $(7.5 \mathrm{~m} / \mathrm{s})$ were obtained near the sidewall surface, but with little damage on the support system. With the gradual increase of explosive charge and slight change of burden, the whole tested sidewall (panel) was then fully destroyed. What causes such totally different results is not yet clear and more importantly, it makes the question of how to design blast in order to effectively investigate the support systems extremely complex.

To find a rational and standard way to design suitable blasts, it was decided to conduct numerical analyses. At this stage, the objective is to investigate the failure mechanisms and further improve the blast design through back-analysing the field experiments. The long term objective of the numerical modelling task is to carry out simulated rockburst experiments numerically instead of physically once proper calibration is reached between the numerical model and underground testing results. A coupled numerical modelling technique was hence used in this study. The blasting was simulated by using finite element method (LS-DYNA) and the dynamic interaction between the blasting generated waves and the rock opening was simulated by using discrete element modelling (UDEC) with the dynamic input from LS-DYNA.

\section{Field experiments}

\subsection{Description}

During 2010-2012, a series of underground experiments were conducted the Kiirunavaara underground iron ore mine which is owned by Luossavaara-Kiirunavaara $A B$ (LKAB) and located in Kiruna, Sweden 
(www.lkab.com). The principal objective of the simulated rockburst experiments was to assess the in situ performance of different ground support systems under dynamic loading. Other pursued objectives included the study of rock ejection, obtaining quantitative data for modelling purposes and investigating the relationship between measured peak particle velocity (ppv) and blast induced damage of the shotcrete/rock surface. The purpose of the setup was to expose the support systems to approximate ppvs of $1.5-3.5 \mathrm{~m} / \mathrm{s}$. The maximum ppv chosen was based on the calculation by using ppv-magnitude-distance relationship (Kaiser et al., 1996) assuming a seismic event with magnitude +3 (Richter scale) located $15 \mathrm{~m}$ away from drift, which has occurred at the Kiirunavaara underground mine.

Adjacent pillars between the crosscuts in the completed production block 9 on the $741 \mathrm{~m}$ level were chosen for the tests. The width of the pillar is approximately $18 \mathrm{~m}$ and the size of a crosscut is $7.0 \mathrm{~m}$ in width $\left(W_{\text {cc }}\right)$ and $5.2 \mathrm{~m}$ in height $\left(H_{\mathrm{cc}}\right)$. Rock types in the tested area comprise 'syenite porphyries' (mainly trachytes to trachyandesites) of variable character. The area is characterised by an intense network of structures in many directions and 817 large and significant fractures were mapped in the area and at least four fracture sets have been discerned. The test sites are shown in Figure 1.

Since tests were conducted either on the left or right sidewall of the crosscuts, only a schematic diagram of the test layout and blast design on the left sidewall is shown with symbols in Figure 2 while the parameters for the symbols at each blast are listed in Table 1. The blasthole was drilled from an adjacent footwall drift in a direction parallel to the crosscut and was around $15 \mathrm{~m}$ long. Two different charge concentrations, each one around $5 \mathrm{~m}$ in length, were used inside the blasthole for generating different dynamic loads on the panel in one blast (charge segment 1 was always loaded near the toe of the blasthole). The blastholes were toe primed and were left unstemmed to vent the gas and further reduce the effect of gas. The burden was designed as $3.5 \mathrm{~m}$ according to previous experience (Olsson et al., 2009) and varied along the tested sidewall due to deviation of drilling combined with irregular profile of the tested panel. Therefore, only the average or effective burden is listed in Table 1. The used explosive was a military type; NSP711 with measured Velocity of Detonation (VoD) of $7,931 \mathrm{~m} / \mathrm{s}$ and density of $1,500 \mathrm{~kg} / \mathrm{m}^{3}$. The reasons for selecting this explosive type were the lower amount of gas production compared to commercial explosive types, high VOD and blasthole pressure resulting in getting more energy through shock wave than the gas expansion, and well known Jones-Wilkins-Lee (JWL equation of state) parameters (Helte et al., 2006) for numerical analysis.

Table 1 Blast design parameters at Tests 1, 2 and 5

\begin{tabular}{|c|c|c|c|c|c|c|c|}
\hline Parameters & Unit & \multicolumn{2}{|c|}{ Test 1} & \multicolumn{2}{|c|}{ Test 2} & \multicolumn{2}{|c|}{ Test 5} \\
\hline Location of blasthole & & \multicolumn{2}{|c|}{$\begin{array}{l}\text { Between crosscuts } \\
\quad 90 \text { and } 93\end{array}$} & \multicolumn{2}{|c|}{$\begin{array}{l}\text { Between crosscuts } \\
93 \text { and } 95\end{array}$} & \multicolumn{2}{|c|}{$\begin{array}{c}\text { Between crosscuts } \\
\quad 95 \text { and } 98\end{array}$} \\
\hline Diameter of blasthole & $\mathrm{mm}$ & \multicolumn{2}{|c|}{115} & \multicolumn{2}{|c|}{152} & \multicolumn{2}{|c|}{152} \\
\hline $\begin{array}{l}\text { Length of blasthole } \\
\qquad\left(L_{\mathrm{c} 1}+L_{\mathrm{c} 2}+L_{s}\right)\end{array}$ & $\mathrm{m}$ & \multicolumn{2}{|c|}{14.7} & \multicolumn{2}{|c|}{15.0} & \multicolumn{2}{|c|}{16.0} \\
\hline $\begin{array}{l}\text { Average height of blasthole } \\
\text { to the floor }\left(H_{b h}\right)\end{array}$ & $\mathrm{m}$ & \multicolumn{2}{|c|}{1.5} & \multicolumn{2}{|c|}{1.6} & \multicolumn{2}{|c|}{1.6} \\
\hline Stemming length $\left(L_{s}\right)$ & $\mathrm{m}$ & \multicolumn{2}{|c|}{4.7} & \multicolumn{2}{|c|}{5.0} & \multicolumn{2}{|c|}{5.0} \\
\hline Effective burden $(B)$ & $\mathrm{m}$ & \multicolumn{2}{|c|}{3.7} & \multicolumn{2}{|c|}{3.9} & \multicolumn{2}{|c|}{3.3} \\
\hline Charge length & $\mathrm{m}$ & $L_{\mathrm{c} 1}=5.0$ & $L_{\mathrm{c} 2}=5.0$ & $L_{c 1}=5.0$ & $L_{\mathrm{c} 2}=5.0$ & $L_{\mathrm{c} 1}=6.0$ & $L_{c 2}=5.0$ \\
\hline Diameter of charge & $\mathrm{mm}$ & 45 & 76 & 98 & 76 & 83 & 94 \\
\hline Charge concentration & $\mathrm{kg} / \mathrm{m}$ & 2.38 & 6.80 & 10.94 & 6.70 & 8.50 & 10.25 \\
\hline
\end{tabular}



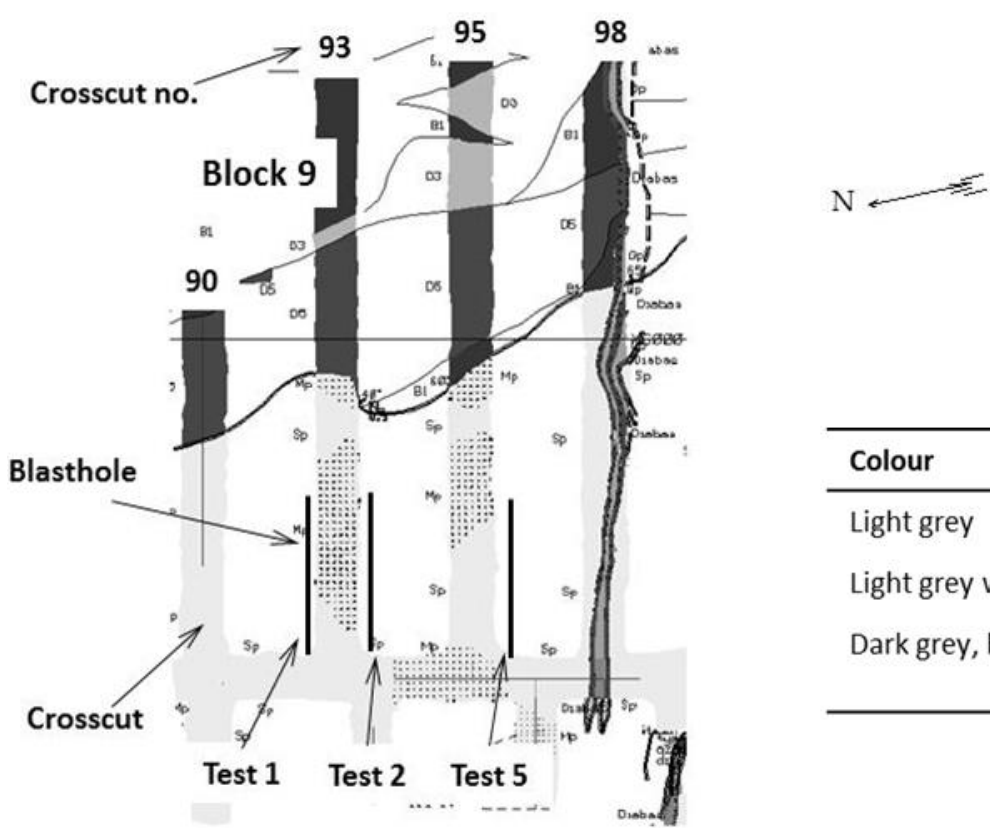

Figure 1 Test sites with legend (black line indicates the location of blasthole for each

test)

(a)

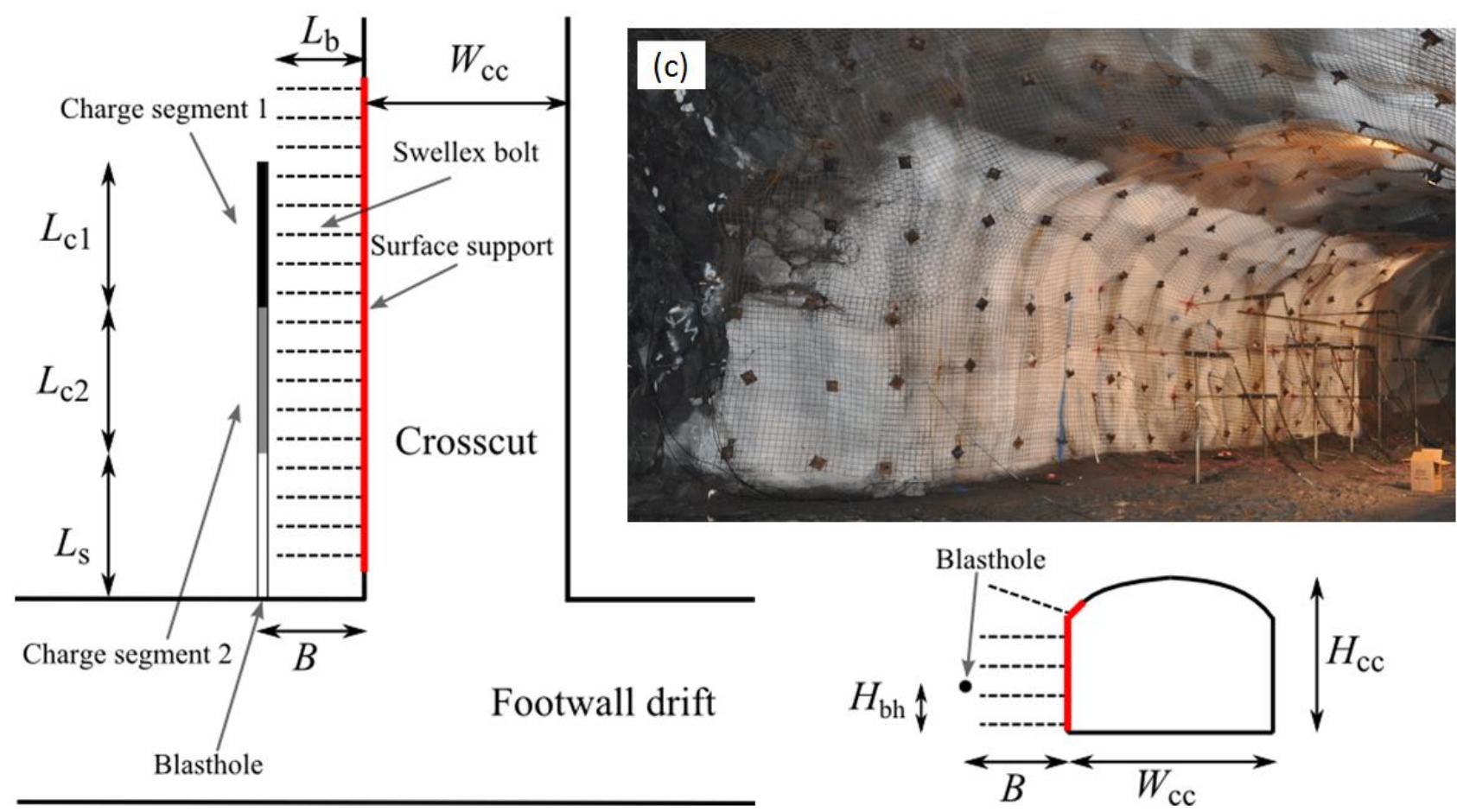

\begin{tabular}{ll}
\hline Colour & Geology Investigation \\
\hline Light grey & syenite porphyry \\
Light grey with dots & nodular syenite porphyry \\
Dark grey, black & $\begin{array}{l}\text { iron ore with variable apatite } \\
\text { and silicate contents }\end{array}$ \\
\hline
\end{tabular}

(b)

\section{Figure 2 Schematic diagram of test layout and blast design. (a) Top view, (b) front view and (c) photo of instrumented side wall in Test 1}

The support system used on the tested sidewall was the LKAB standard support in burst prone areas of the mine consisting of $100 \mathrm{~mm}$ fibre reinforced shotcrete $\left(40 \mathrm{~kg} / \mathrm{m}^{3}\right.$ steel fibre), welded steel mesh with $5.5 \mathrm{~mm}$ in diameter and $\mathrm{c} / \mathrm{c} 75 \mathrm{~mm}$, and Swellex bolts with $3 \mathrm{~m}$ in length $\left(L_{\mathrm{b}}\right)$ and c/c $1 \mathrm{~m}$.

The instrumentation was designed to provide data for different objectives and included: dozens of uniaxial shock accelerometers (PCB 350 B03), mostly mounted approximately $0.20 \mathrm{~m}$ behind rock surface in all tests 
(except two which were installed $0.75 \mathrm{~m}$ and two which were installed $1.50 \mathrm{~m}$ behind rock surface in Test 2); high-speed camera (Casio EX-F1, 300 frames per second) used to estimate block ejection velocity; displacement probes (spears) (Olsson et al., 2009) used to measure the maximum displacement at certain points (where larger movements were expected) on the panel surface; laser scanning (Leica HDS 6000) used to measure the surface deformation before and after each blast; distance sensor (SICK OD Value) using laser technology for dynamic displacement measurements; gas pressure transmitter (ED 517) for gas detection; Time Domain Reflectometry (TDR) technology (F2-660BV) used to investigate the fractures inside the pillar and observation holes $(64 \mathrm{~mm}$ ) for borehole camera (RobiCam) logging before and after the blast. It should be noted that TDR cables were normally installed perpendicular to the panel and at nearly the same height of blasthole axis inside the burden, while some were also installed at the height around $0.7 \mathrm{~m}$ above the height of blasthole axis in Test 1.

Six tests have been conducted so far. In order to compare different tests, only the results from three of the tests were considered in this paper as these tests had similar blast design and measurements. Full details on the tests, can be referred to final report (Shirzadegan et al., 2013).

\subsection{Experimental results}

During the analysis stage, the recorded accelerometer data were integrated to obtain velocities and displacements during the blast. Panel profiles were calculated using a laser distance tool, which measured the distance to the wall from set points along the axis of the crosscut. Profiles were taken before and after the final blast for each panel. The data were analysed using a contour mapping program to quantify any bulking or ejection of broken rock.

Throughout the test program, different quantities of explosives and burdens were used to generate varying levels of seismic intensity. As a result of numerous variables associated with blasting, any assessment of support performance was based upon measured vibration and displacement levels rather than linked to the quantity of explosives. The summary of the test results is listed in Table 2. It can be seen from Table 2 that the results from each test show certain variability, mainly due to different distances from sensors to the axis of blasthole (non-plane wave) and two different charged segments used at these tests and also many variables poorly controlled in such field tests, e.g. geology, discrete discontinuities in the rock mass, varying burdens (due to irregular surfaces), etc. More detailed results can be found in report (Shirzadegan et al., 2013).

Table 2 Summary of the test results

\begin{tabular}{lccccccc}
\hline & Unit & \multicolumn{2}{c}{ Test 1 } & \multicolumn{2}{c}{ Test 2 } & \multicolumn{2}{c}{ Test 5 } \\
& & CS1 & CS2 & CS1 & CS2 & CS1 & CS2 \\
\hline ppv by accelerometers & $\mathrm{m} / \mathrm{s}$ & $1.0-4.0$ & $2.2-6.8$ & $2.4-7.5$ & $2.3-6.9$ & 5.9 & 7.0 \\
$\begin{array}{l}\text { Peak displacement by } \\
\text { accelerometers }\end{array}$ & $\mathrm{mm}$ & $3-35$ & $8-69$ & $5-103$ & $2-110$ & 40 & $\begin{array}{c}\text { Fully } \\
\text { damaged }\end{array}$ \\
$\begin{array}{l}\text { Displacement by spears } \\
\text { Displacement by laser scanning }\end{array}$ & $\mathrm{mm}$ & $10-30$ & $10-70$ & $40-110$ & $80-100$ & - & - \\
$\begin{array}{l}\text { Detected fracture locations } \\
\text { behind surface by TDR }\end{array}$ & $\mathrm{m}$ & $3-20$ & $20-50$ & $10-120$ & $10-100$ & - & - \\
\hline
\end{tabular}

Note: ' - ' indicates no measurement; 'CS' is the abbreviation of Charge Segment; ' ${ }^{* \prime}$ indicates that the values were obtained from TDR cables installed at the height around $0.7 \mathrm{~m}$ above the height of blasthole axis. 


\subsubsection{Tests 1 and 2}

The level of damage was assessed through visual inspection. As a result of the blast, the collar of the blasthole near the footwall drift in Tests 1 and 2 were destroyed. No obvious damage was observed on bolts and mesh; however, some fractures on the shotcrete surface were detected as shown in Figures 3 and 4. The fractures were a little wider in Test 2 than Test 1 due to larger amount of explosives used in Test 2. TDR cable measurements showed fractures occurring behind the surface both in Test 1 and 2, see Table 2 .

ppvs by accelerometers installed approximately $0.20 \mathrm{~m}$ behind rock surface are listed in Table 2 . As can be seen, the ppvs were increasing in the same test as the explosive amount was increasing. There was good agreement regarding displacement between different measurements and the results are listed in Table 2 .

\subsubsection{Test 5}

Test 5 used almost the same amount of explosives at higher charged segment as Test 2 but slightly smaller burden than Test 2 . But, the results were surprising. The panel and part of the pillar completely collapsed and broke into large blocks of rock after the blast (see Figure 5). The recorded highest ppv was around $7.0 \mathrm{~m} / \mathrm{s}$ before the signal was clipped. As only accelerometers were installed, there are no results from spear, TDR or laser scanning in Table 2.

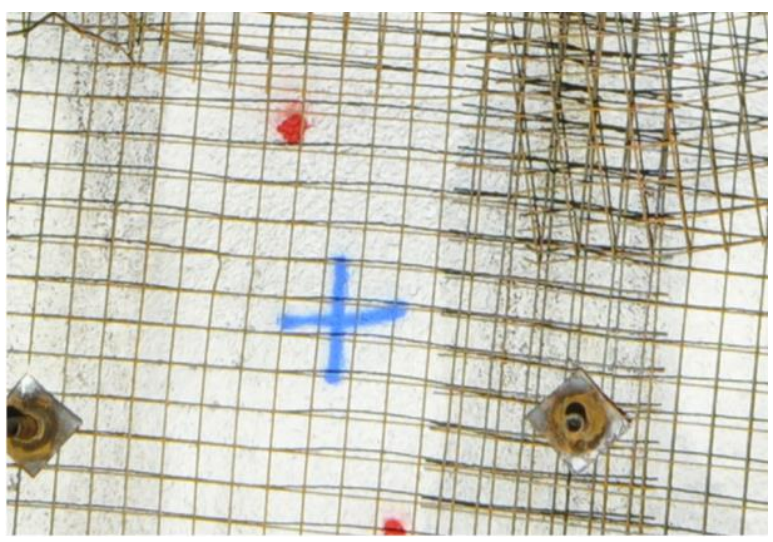

(a) Before blasting

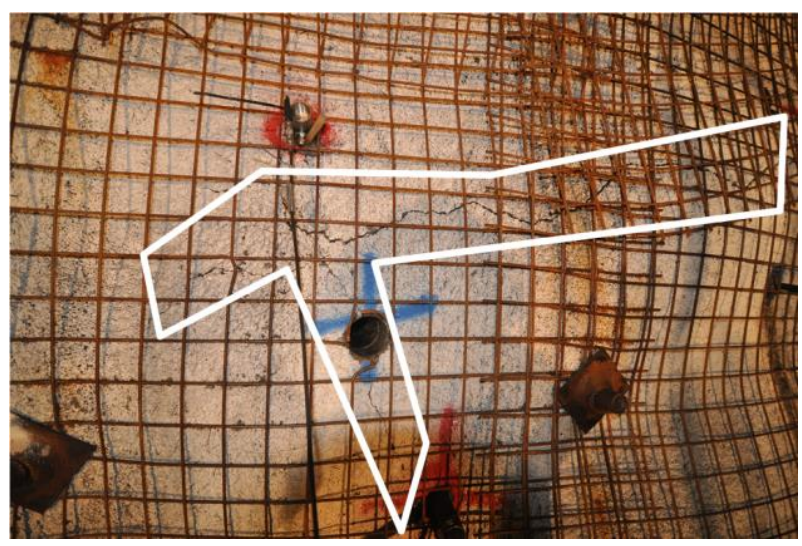

(b) After blasting

\section{Figure 3 Comparison of damage on the panel in Test 1 (fractured area is outlined by closed white line)}

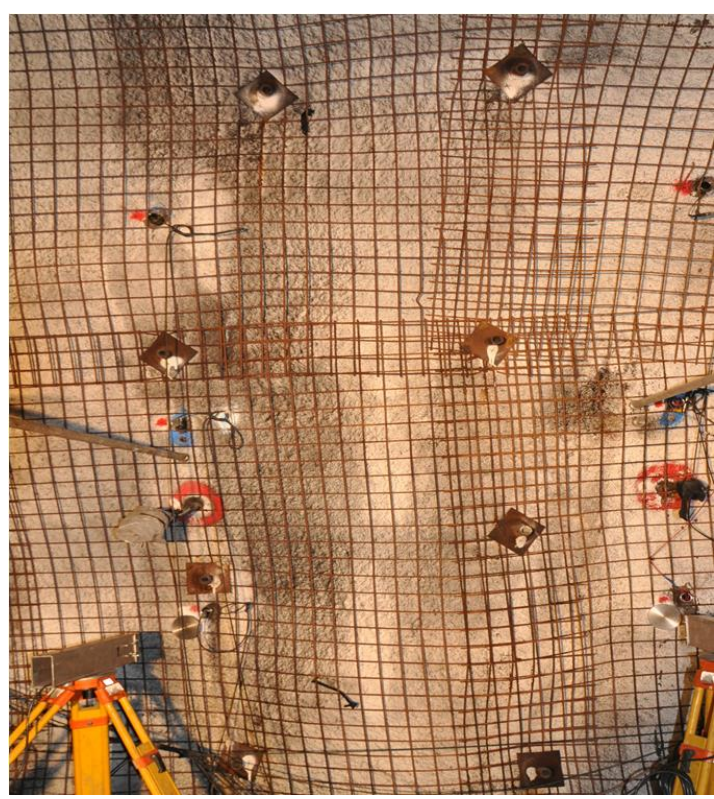

(a) Before blasting

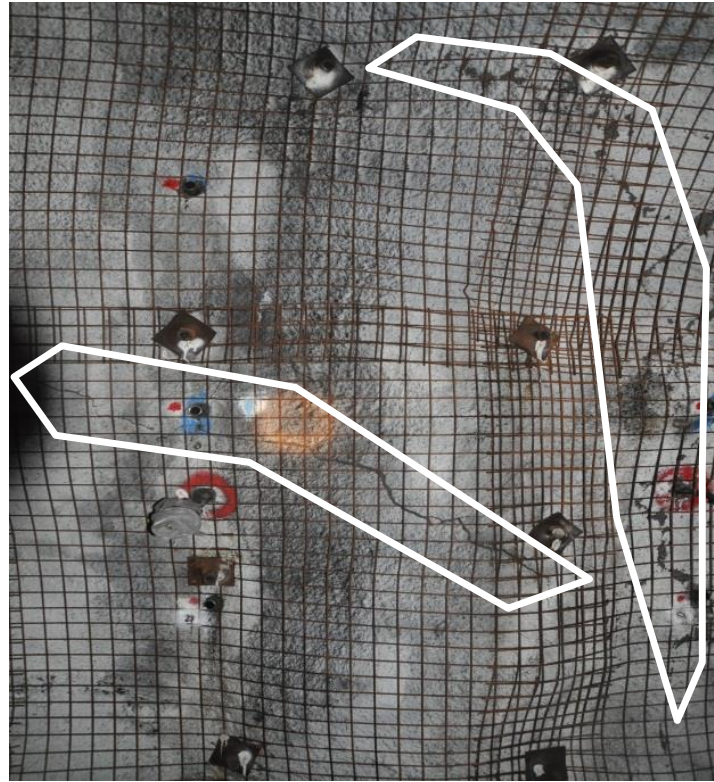

(b) After blasting 


\section{Figure 4 Comparison of damage on the panel in Test 2 (fractured area is outlined by closed white line)}

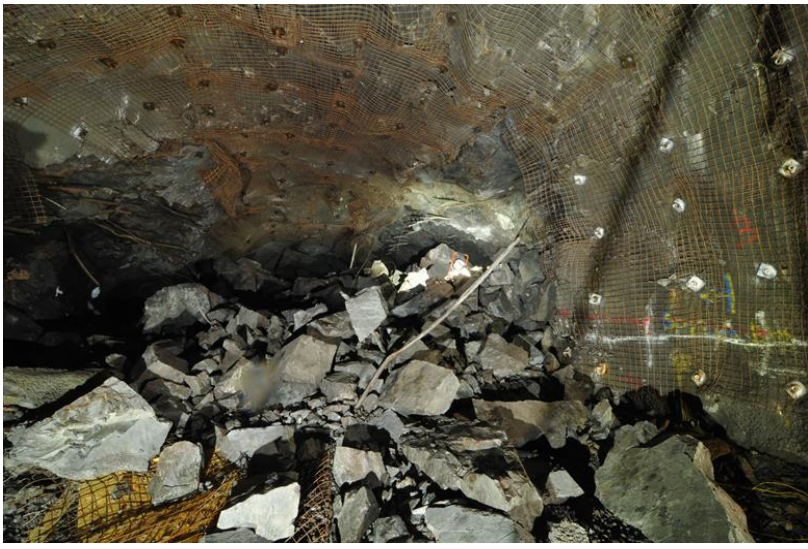

(a) Before removing fragments

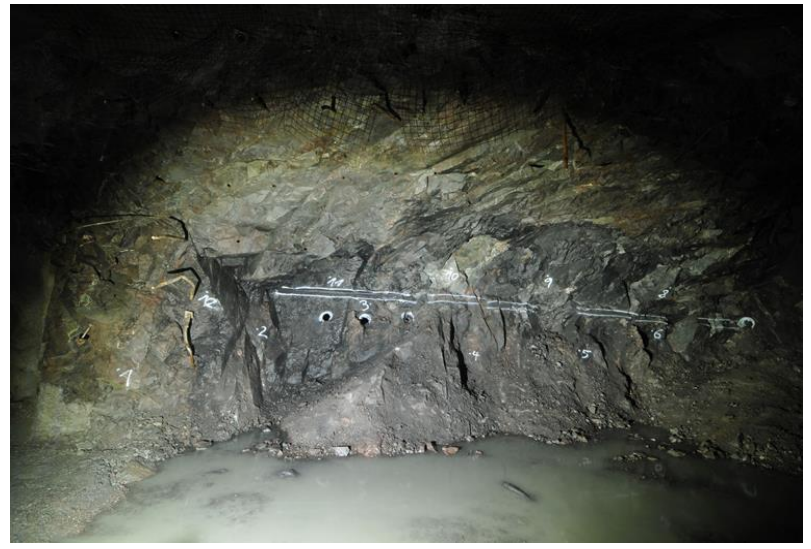

(b) After removing fragments

\section{Figure 5 Damage on the panel and within the pillar after blasting in Test 5}

\section{Numerical back-analysis}

Simulation of blasting in a rock mass and its action on opening and rock support is highly complicated because it involves an explosion of high-energy explosive, wave propagation through rock mass, dynamic response of an opening as well as the interaction between rock and support system. LS-DYNA is specially designed to solve a wide variety of non-linear problems including the explosion of condensed explosive material in gas, fluid and solid (Hallquist, 2006). However, it is a continuum-based code and cannot effectively incorporate rock discontinuities into the computational model and also lacks application in simulating support system. UDEC has been widely used to simulate the rock mass behaviours, especially discontinuity as well as support systems, but cannot model the explosion. Therefore, a fully coupled UDEC and LS-DYNA analysis for simulated rockburst tests (underground blasting) has been conducted here. The blast loads were calculated by LS-DYNA which provided the boundary loading input to the UDEC model for studying the wave propagation and the induced dynamic effects on rock mass and support system. The decision to use UDEC (two dimensions) was based on the limited time available to construct a 3D model, the ability of implementing natural discontinuities into the model and the wide range of structural elements already built into the code. However, in this analysis, the natural discontinuities and support system were not considered as the focus of the numerical modelling was to investigate the failure mechanisms in the field experiments. Due to page limitations, the detailed description regarding the numerical model and the main comparison below is related only to field Test 2.

\subsection{LS-DYNA model}

\subsubsection{Problem statement and material properties}

The problem featured a $10 \mathrm{~m}$ explosive column with a diameter of $97 \mathrm{~mm}$ in a $15 \mathrm{~m}$ long blasthole with a diameter of $152 \mathrm{~mm}$. No stemming (air) was used in the remaining blasthole. The detonation process was simulated by a three dimensional model. Non-reflecting, i.e. viscous boundaries, were introduced around the outer perimeter of the domain to eliminate wave reflections. The model was a cylinder with the height $25 \mathrm{~m}$ and diameter $20 \mathrm{~m}$.

The rock was modelled with the RHT material model, which is an advanced plasticity model for brittle materials such as concrete and rock. The RHT model was developed by Riedel, Hiermaier and Thoma (Riedel et al., 1999) for dynamic loading of concrete and implemented in LS-DYNA in 2011 (Borrvall and Riedel, 2011). The material model is composed of three pressure dependent surfaces - the failure surface, the elastic limit surface and the residual surface-combined with EOS (equation of state). The RHT model 
includes a damage model based on continuum damage theory. The calibrations of parameters can be found in reports (Schill, 2012; Zhang et al., 2013).

\subsubsection{Blast loading in UDEC model}

The actual blasthole size of $152 \mathrm{~mm}$ cannot be used in UDEC as detonation creates a crushed zone around the hole that causes enormous energy absorption which cannot be readily modelled by UDEC. To avoid the complicated behaviour of a crushed zone, the explosion input to UDEC, in terms of the velocity-time history at the Crushed Zone Boundary (CZB) was computed via LS-DYNA (see Figure 6). In LS-DYNA, the crushed zone can be identified by the damage level (see Figure 6) since the embedded RHT model can simulate both tensile and compressive failure with a damage model.

\subsection{UDEC model}

\subsubsection{Problem statement and material properties}

The problem featured a blast load acting on a CZB with a diameter of $1.31 \mathrm{~m}$ near a crosscut with the size of $7.0 \times 5.2 \mathrm{~m}$. It can be treated as a plane-strain case, in which the $X$ and $Y$ axis lie on the cross section with the origin at the centre of the blasthole. The model had a size of $60 \times 60 \mathrm{~m}$ (two dimensions) and is shown in Figure 7. The different burdens $(3.3,3.9,5$ and $8.5 \mathrm{~m}$ ) have been studied in order to investigate their effects. The mechanical properties of intact rock used in the analysis were from Malmgren and Nordlund (2008) and Brandshaug (2009) and are listed in Table 3.

The stress state in the vicinity of the crosscut is expected to be important to the potential damage and blasting-induced fracture propagation. Hence, the stress state in the current UDEC model was from previous numerical studies of Kiirunavaara (Malmgren and Sjöberg, 2006) that considered a mine-scale analysis. The stress level determined at the tested site were $-16.5 \mathrm{MPa}$ and $-11.3 \mathrm{MPa}$ along the $\mathrm{x}$ and $\mathrm{y}$ direction respectively.

\subsubsection{Dynamic modelling considerations}

For a dynamic analysis, the damping in the numerical model is an important factor and should attempt to reproduce the energy losses in the natural system when subjected to dynamic loading. Rayleigh damping is commonly used in UDEC to provide damping that is approximately frequency-independent over a restricted range of frequencies. For geological materials, the damping ratio commonly falls in the range of 2 to $5 \%$ of critical (Itasca Consulting Group, 2011) and $2 \%$ is used in this analysis. The dominant frequency required in UDEC can be determined by performing a spectral analysis (see Figure 8) of typical velocity input, see Figure 6(b). The value adopted for the modelling was $391 \mathrm{~Hz}$. Non-reflecting, i.e. viscous, boundaries were introduced around the outer perimeter of the domain to eliminate wave reflections.

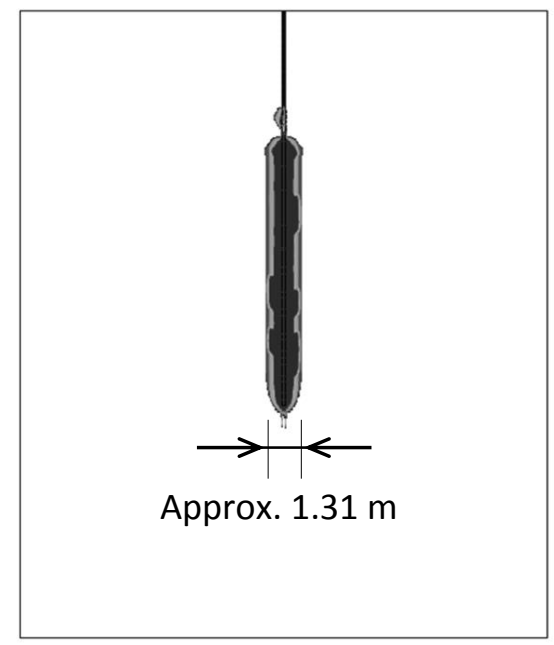

(a) Damage level around blasthole

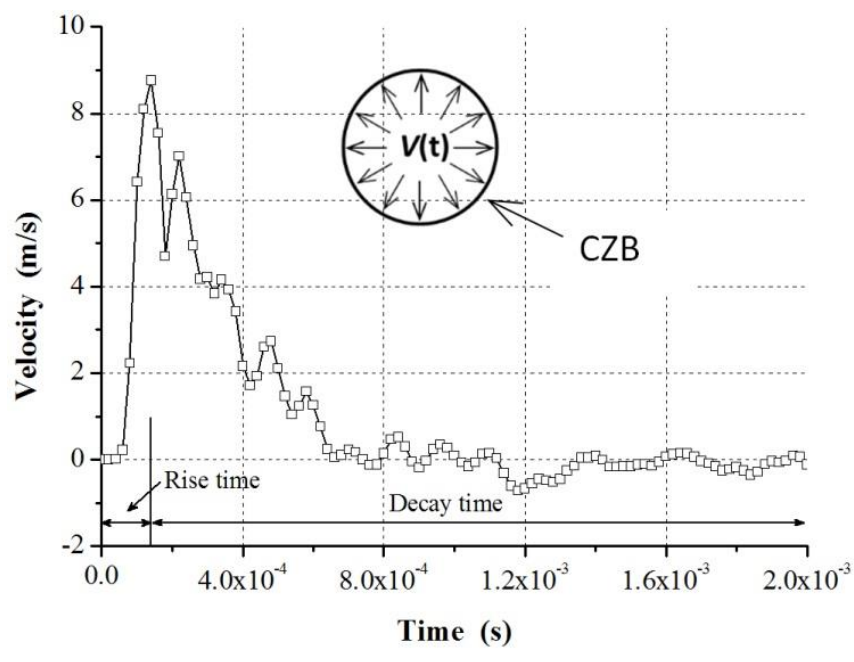

(b) Velocity time curve on the CZB 
Figure 6 Determination of CZB and velocity time curve on the CZB

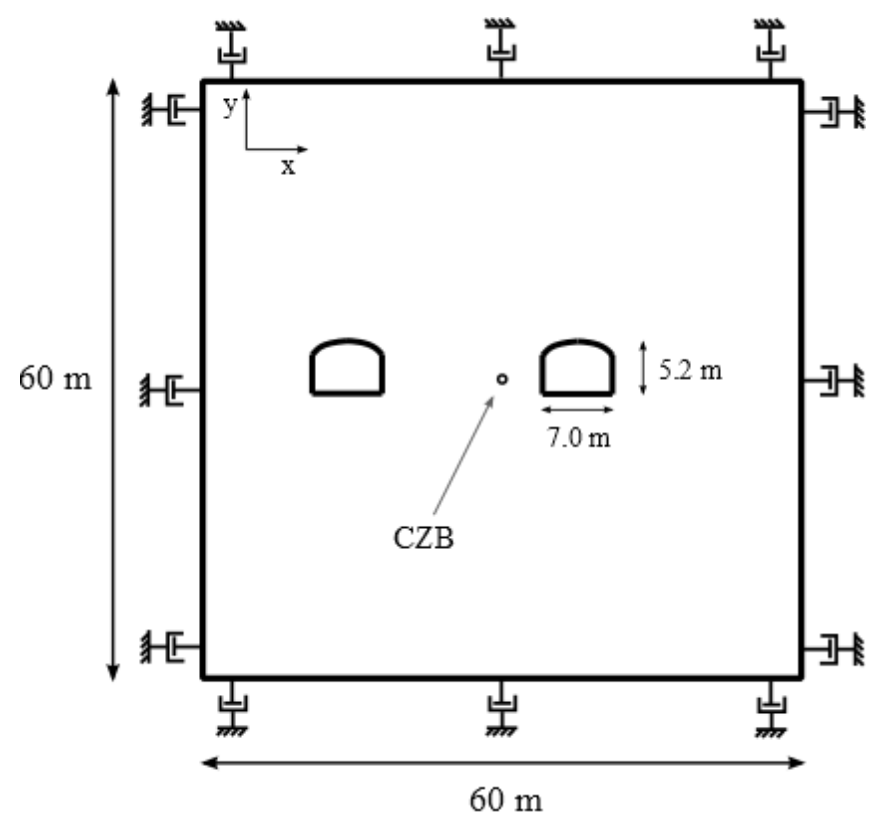

Figure 7 UDEC model

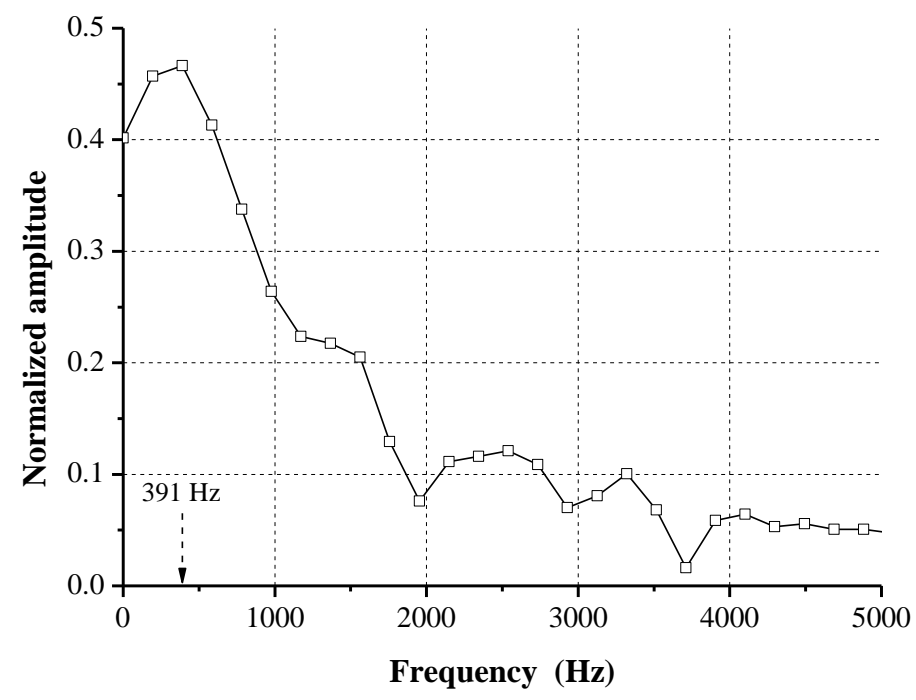

Figure 8 Power spectrum analysis of input velocity-time history

Table 3 Mechanical properties of intact rock

\begin{tabular}{cccccc}
\hline$E(\mathrm{GPa})$ & $\boldsymbol{v}$ & $\boldsymbol{\rho}\left(\mathrm{kg} / \mathrm{m}^{3}\right)$ & $\boldsymbol{C}(\mathrm{MPa})$ & $\boldsymbol{\varphi}$ & $\sigma_{\mathrm{t}}(\mathrm{MPa})$ \\
\hline 70 & 0.27 & 2,800 & 31 & 61 & 10 \\
\hline
\end{tabular}

\section{$4 \quad$ Numerical results}

\subsection{Velocity and displacement analysis}

Accelerometers 9 and 17 were both located at $0.2 \mathrm{~m}$ behind the middle of the panel surface (higher charged segment) and their heights were close to the height of the axis of blasthole. The integrated velocity-time curves at those two measurement points are plotted together with the numerical results at 
the middle of the two measurement points in Figure 9(a). Also the velocity integrated from recording of accelerometer 18 located $0.75 \mathrm{~m}$ behind the surface is compared with numerical modelling and plotted in Figure 9(b). It can be seen from Figure 9 that the velocity time curves from field measurements and numerical modelling show approximate variation tendency in waveform but the peak value and duration from the numerical modelling is lower and shorter than the field measurements.

Maximum displacement obtained from numerical modelling is around $3.5 \mathrm{~mm}$ and is much smaller compared to the field measurements. Detailed explanation can be found in Section 5.1.

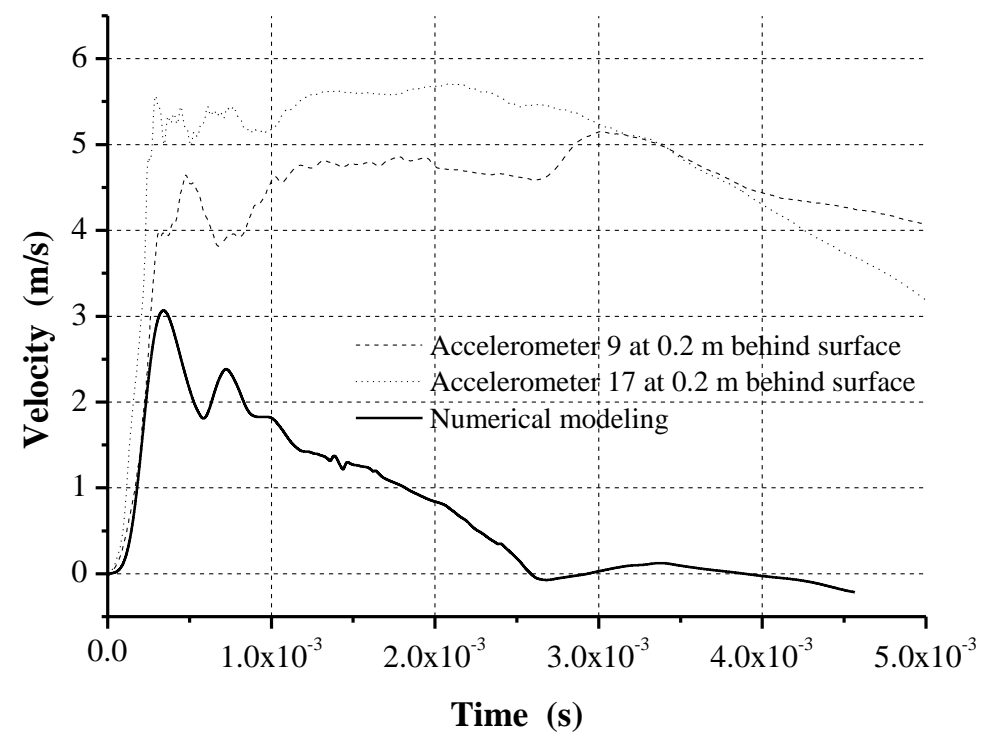

(a) $0.2 \mathrm{~m}$

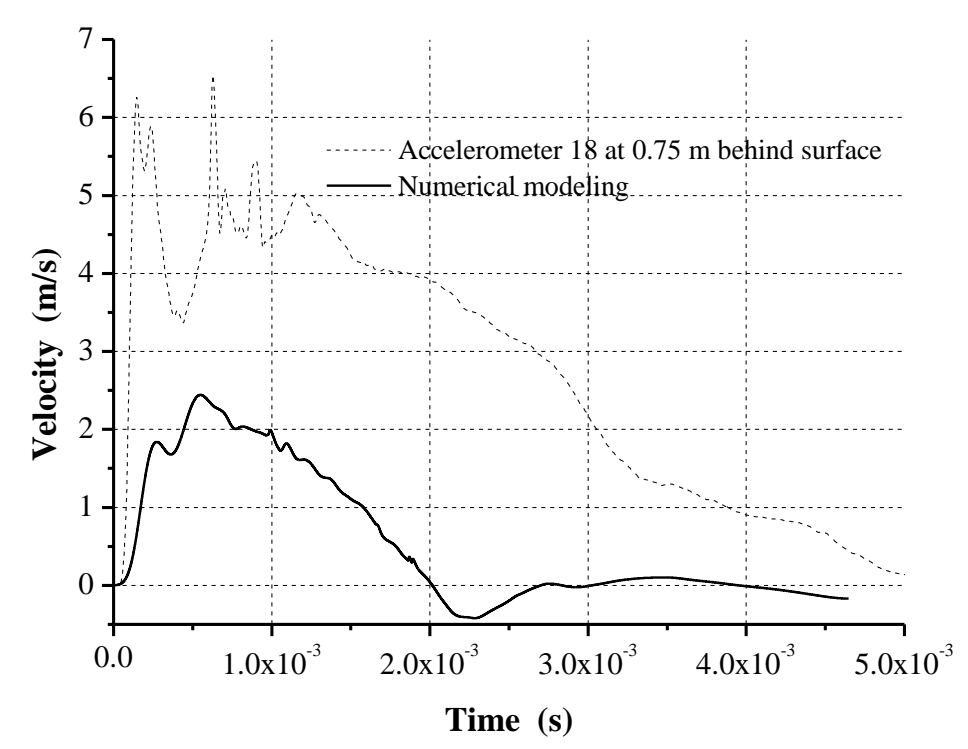

(b) $0.75 \mathrm{~m}$

Figure 9 Comparison of velocity-time curves between field test and numerical modelling (points are located at $0.2 \mathrm{~m}$ and $0.75 \mathrm{~m}$ behind the tested panel in Test 2)

\subsection{Fracture propagation pattern analysis}

The fracture propagation patterns for burdens $3.9 \mathrm{~m}$ and $3.3 \mathrm{~m}$ are shown in Figures 10(a) and (b) which are corresponding to the results from the field Tests 2 and 5 (higher charged segment) in which nearly the same amount of explosives has been used. 


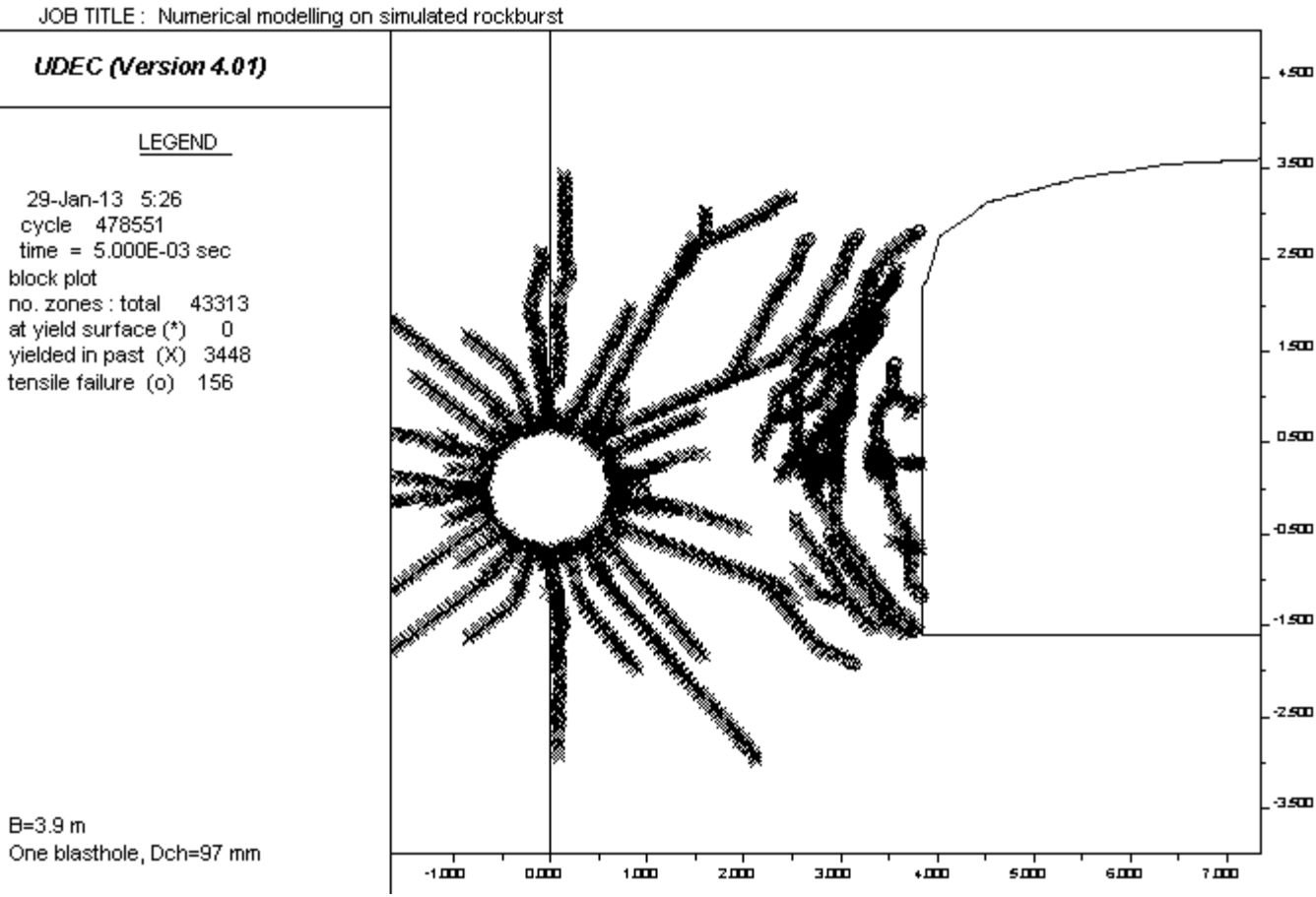

(a) Burden $=3.9 \mathrm{~m}$ (Test 2)

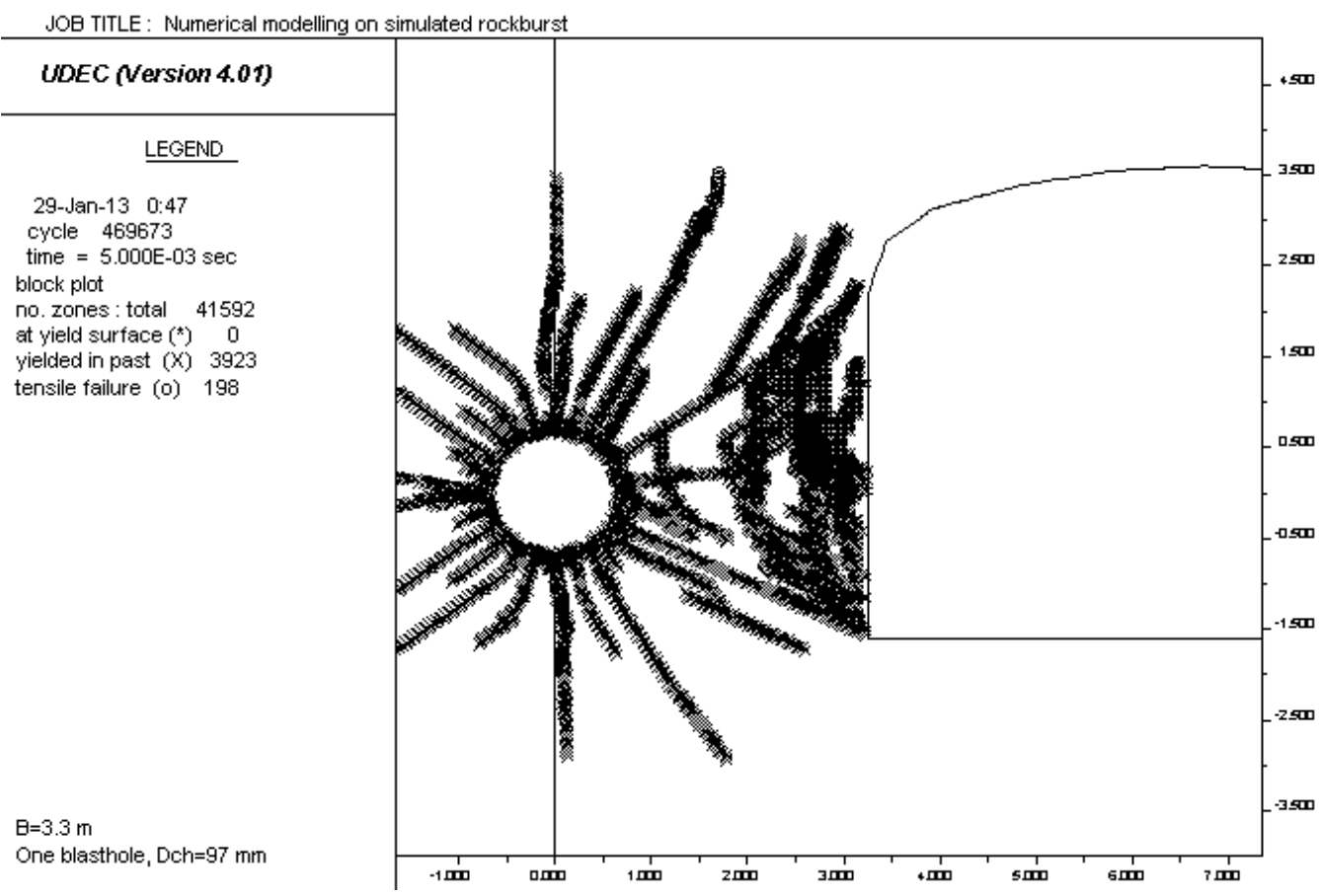

(b) Burden $=3.3 \mathrm{~m}$ (Test 5)

\section{Figure 10 Numerical simulations of fracture propagation pattern in Test 2 and Test 5 (higher charged segment)}

These simulations resulted in a large number of radial fractures radiating from the CZB, fractures parallel to the panel surface in the region near the free face, and a large cone-shaped 'plug' of material moving outwards away from the CZB, with extensive yielding occurring along and within the boundary of this cone. The result presented in Figure 10(b) is quite representative of the aftermath of Test 5 in which the test panel and part of the pillar were completely destroyed. In comparison to one another, the radial fractures are longer within the cone-shaped area and there are more fractures penetrating into the free surface and 
spreading within the cone-shaped area for smaller burden than for larger one. In Figure 10(a), the fractures parallel to the free surface in the middle height of the panel are located $0.5 \mathrm{~m}, 0.9 \mathrm{~m}$ and $1.3 \mathrm{~m}$ behind the surface respectively, which supports the TDR measurements by which the newly created fractures have been identified at $0.5 \mathrm{~m}$ and $1.1 \mathrm{~m}$ in Test 2 .

\section{Discussion}

\subsection{Limitation of numerical modelling}

As the objective of the numerical modelling was to investigate the mechanisms and help to improve the blast design, the outcome gives some practical guidelines rather than detailed blast design analysis in which the detailed geological structure and calibration of model should be considered. Even though UDEC is a discontinuum-based code, it cannot model the fracturing and ejecting of material related to newly created fracture surfaces. Instead, the ppvs monitored near the surface and the fracture propagation patterns are compared with the field measurement and observation. However, it should be noted that it is still possible to simulate block movement and separation from rock mass in UDEC by incorporating the existing natural discontinuities into the model and assigning specific parameters to each discontinuity. The effect of natural discontinuities is being investigated and more detailed numerical analyses will be published later.

As both LS-DYNA and UDEC are incapable of simulating the penetration of explosive gases into fractures, only the effect of shock wave on the rock mass during blasting is simulated. Therefore, the run time used in the numerical model was $5 \mathrm{~ms}$ which was enough to consider wave propagation and its reflection as the input dynamic load decays to near zero after a duration of $2 \mathrm{~ms}$. Results from gas pressure transmitter installed parallel to and $1 \mathrm{~m}$ away from the blasthole in Test 1 indicated that the positive pressure occurred $36 \mathrm{~ms}$ after initiation of the explosives and reached its maximum $115 \mathrm{~ms}$ after initiation (Shirzadegan et al., 2013). According to the playback of recorded video from high speed camera, it was found that explosive gases vent through the panel face several hundred milliseconds after firing. It also demonstrated that the conclusion drawn from the numerical modelling only considered the shock wave.

Again, as this analysis was focused on the failure mechanisms and there were no detailed pull-out test results available for super Swellex, the ground support was not simulated for this paper. However, the effect of support system was indirectly studied by applying shotcrete and rebar in one model. The results only showed minor changes in ppvs and fracture propagation patterns which were the foci in this paper. Since the shock wave hits the panel rapidly, the support will first move together with the rock mass as a whole without restraining the rock mass markedly before fractures are generated. That explains why the ppvs are not greatly affected when support system is applied.

Based on the above mentioned limitations as well as several issues, the main reasons why there were certain discrepancies regarding velocity and displacement between numerical modelling and field measurements can be explained as follows. The calculation from LS-DYNA model might give lower input (velocity amplitude) to the UDEC model, which has been reported by Bouamoul et al. (2008). The authors who have proposed and implemented the RHT model into LS-DYNA ever calibrated the numerical calculation method by comparing numerical results with a penetration test (Riedel et al., 1999). The comparison showed that the calculated displacement amplitude is close to the measurement but the waveform differs. In addition, wave amplification around the fractured zone has been observed in the field. However, the effects on velocity and displacement have not been investigated here since the discontinuities are not considered in the model. Furthermore, ignoring natural existing discontinuities will also cause less displacement since opening and/or slip of the discontinuities are not taken into account. Finally, UDEC is not capable to simulate fracturing and separation within intact material, hence the calculated displacement will most likely be lower than the field measurement if new fractures have indeed been created.

In summary, the discrepancies between numerical modelling and field measurements could originate from both LS-DYNA and UDEC model. More parameter sensitivity analyses need be conducted in order to better 
calibrate the model. As there is a large difference in waveform (duration) of velocity-time curve between numerical results and field measurement observed in Figure 9, and LS-DYNA may give shorter or longer duration of dynamic input (Riedel et al., 1999), the velocity-time curve on CZB has been adjusted by tripling the decay time but keeping rise time unchanged (see the definition in Figure 6(b)). The results in Figure 11 based on the waveform modification have shown better agreement between numerical modelling and field measurements.

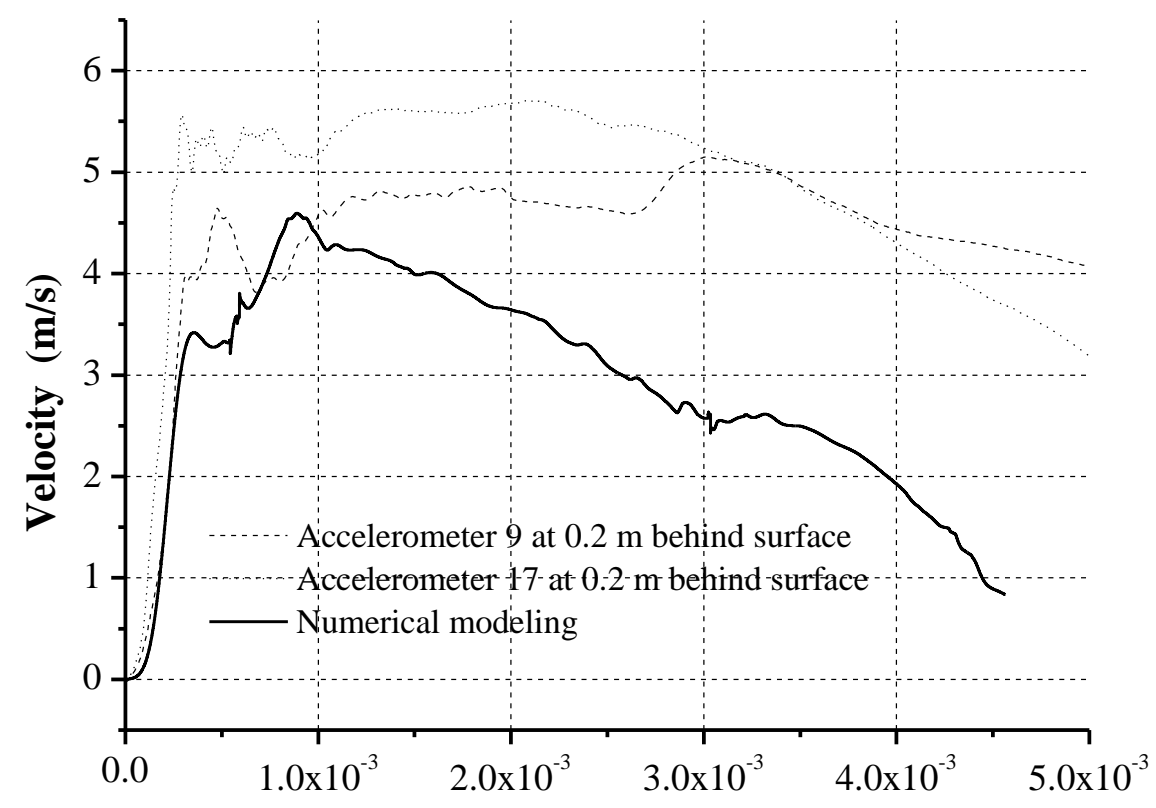

Time (s)

(a) $0.2 \mathrm{~m}$

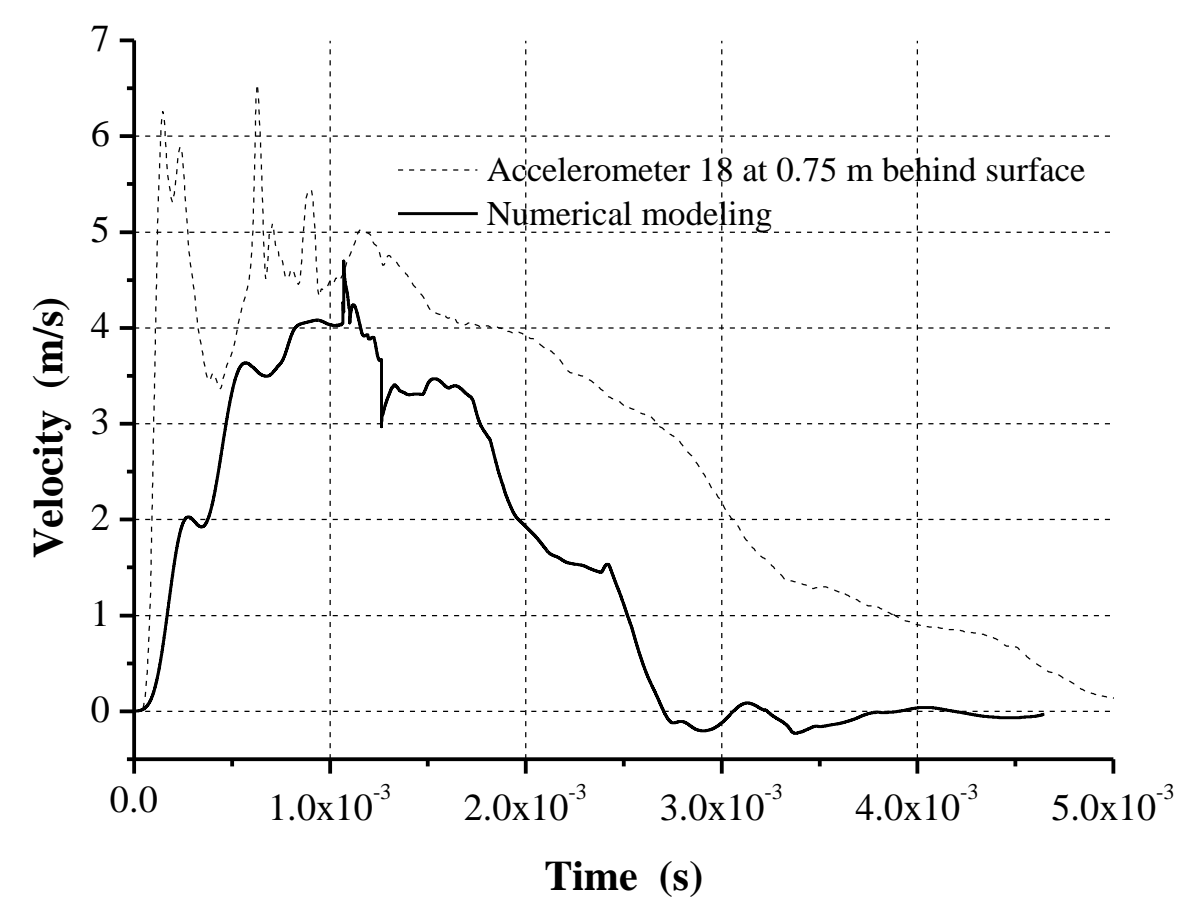

(b) $0.75 \mathrm{~m}$

Figure 11 Comparison of velocity-time curves between field test and numerical modelling with modified input of waveform (points are located at $0.2 \mathrm{~m}$ and $0.75 \mathrm{~m}$ behind the tested panel in Test 2) 


\subsection{Failure mechanism analysis}

As it is shown in Figure 10(b), when burden is $3.3 \mathrm{~m}$ which was the case in Test 5 , a large cone-shaped area of material moving outwards away from the CZB has been generated, with extensive yielding occurring along and within the boundary of this cone. The extensive yielding within the cone-shaped area represents newly created fractures which will cut the rock within the area into small blocks. Since the radial fractures emanated from CZB provide explosive gases enter into the cone-shaped area, the venting of gases could penetrate into the densely clustered fractures and push the small blocks generated by newly created fractures away from the rock mass. This is what has been observed in Test 5 as shown in Figure 5 . There are radial fractures within the pillar and some subparallel fractures near the panel surface in Figure 10(a) when the burden is $3.9 \mathrm{~m}$ which was the case in Test 2. Despite this, the cone-shaped area is not fully created. This is because the fractures have not penetrated into the surface and the fractures inside the pillar have not coalesced. Correspondingly, there are few small blocks created by fractures inside the pillar. Therefore, the venting of gases did not have enough energy to push such large blocks out of the rock mass. The pillar was therefore still standing at the tested site after blasting.

\subsection{Improvement of blast design}

By performing the comparison between Tests 1,2 and 5 experimentally and numerically, it can be concluded that the responses of the panel and pillar are sensitive to the amount of explosives as well as the burden which seems more critical. It seems that the use of a single blasthole may have been insufficient to test the support satisfactorily since it is affected by the creation of a cone-shaped area formed by radial fractures. However, the ejection caused by fault-slip induced seismic event is driven by reflected stress wave which creates fractures parallel or subparallel to the surface. So, successful efforts when conducting simulated rockburst experiments should focus not only on how to minimise the influence of gases but also on how to reduce the risk of cone-shaped failure or cratering effect. In fact, if the risk of cone-shaped failure could be reduced, then the gas effects will automatically be diminished as there is no access for gases to enter. Based on the short discussion presented above, multiple blasts with zero delay and slightly larger burden $(>5 \mathrm{~m})$ is proposed in order to generate a more planar-like wave and reduce radial fracturing. Considering the difficulties in controlling the drilling deviation of blastholes, two blastholes are recommended in practical application.

Two numerical models are constructed with the same blasthole diameter and amount of explosives as had been used in Test 2 . Figure 12 shows the results from numerical modelling. It can be seen that the parallel or subparallel fractures have been created without forming any cone-shaped area both for $5.0 \mathrm{~m}$ burden and $8.5 \mathrm{~m}$ burden. 


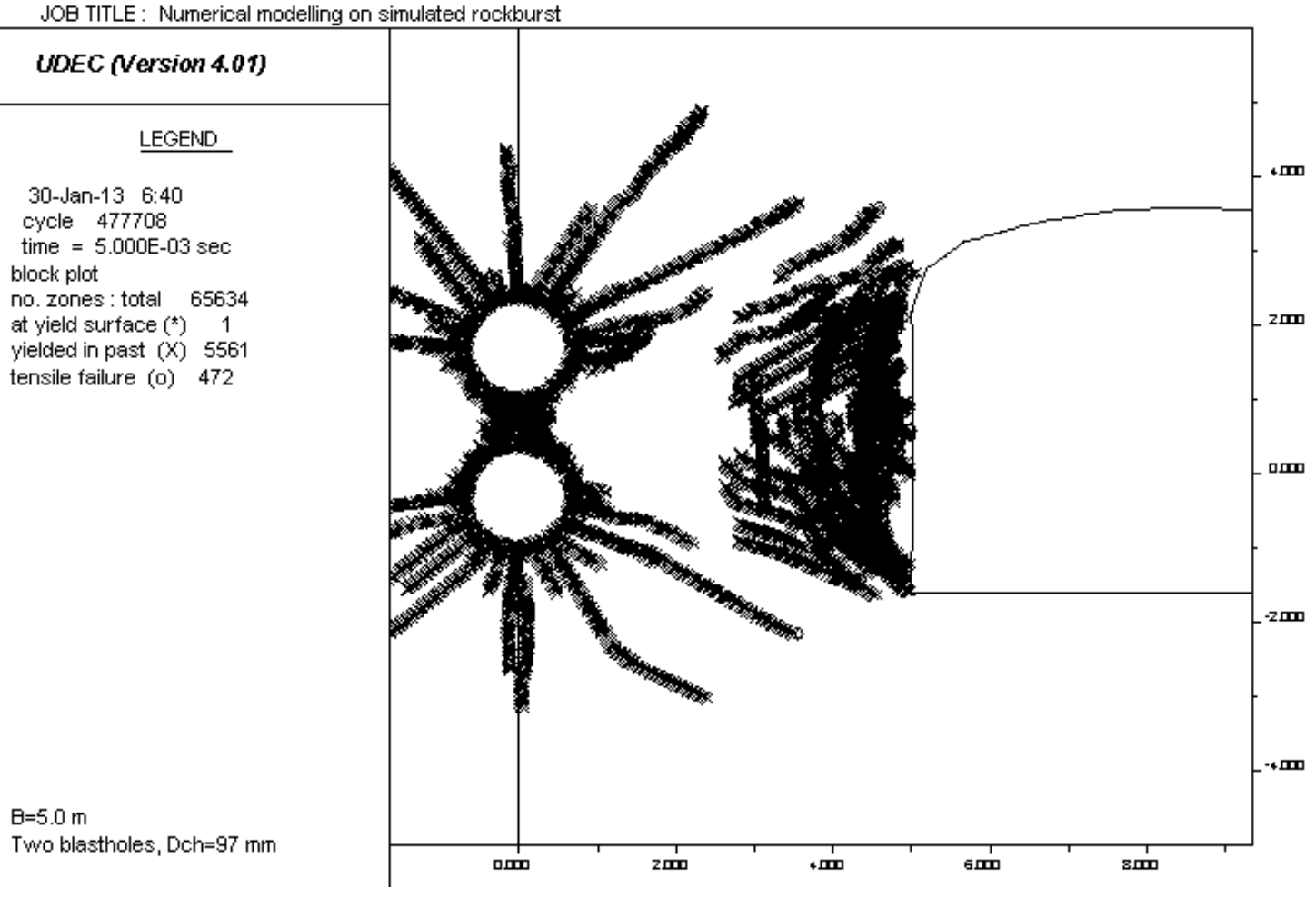

(a) Burden $=5.0 \mathrm{~m}$

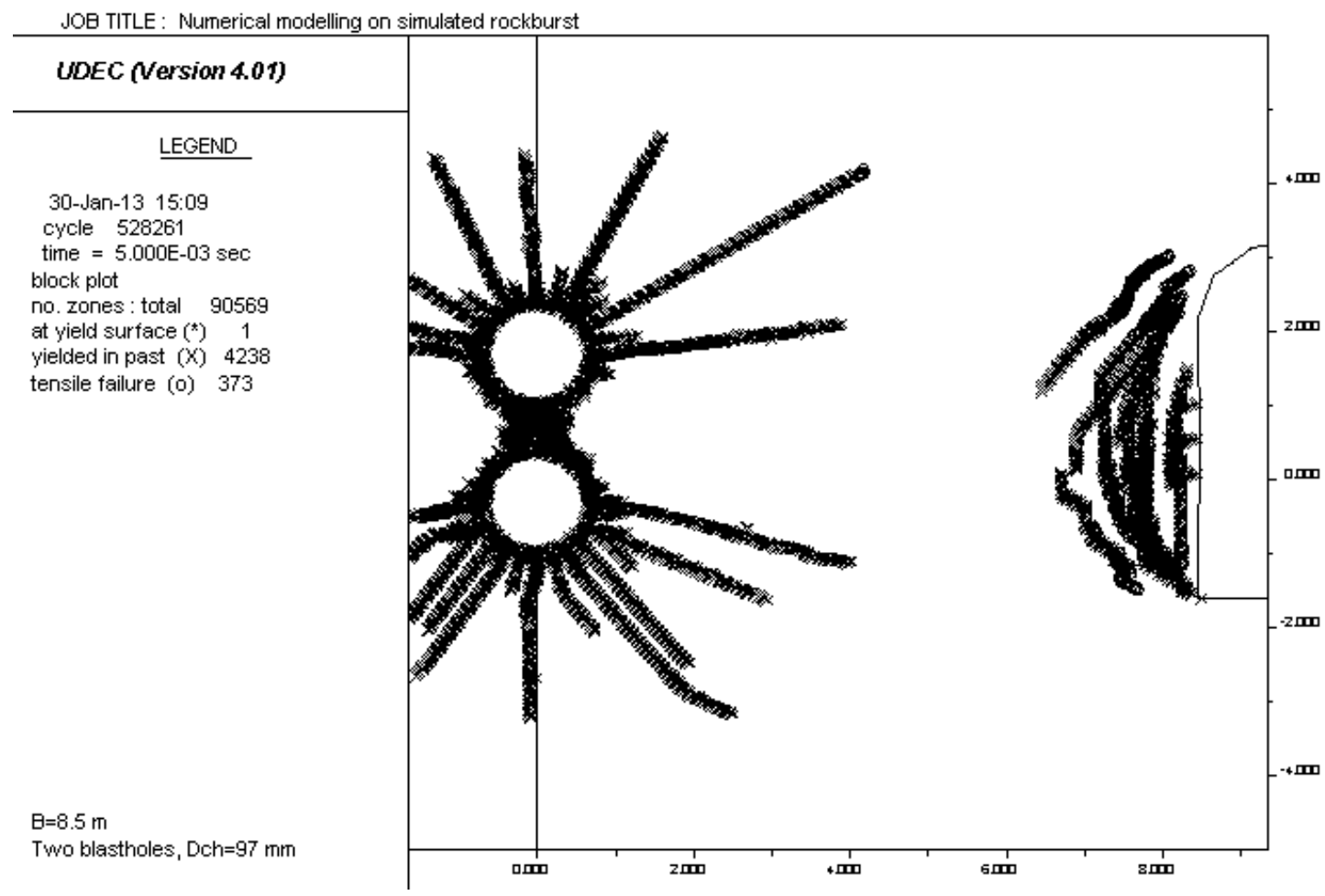

(b) Burden $=8.5 \mathrm{~m}$

Figure 12 Numerical simulation of fracture propagation pattern with two blastholes and larger burdens 


\section{Conclusions}

In order to understand the results of the simulated rockburst test conducted at Kiirunavaara underground mine, a series of coupled numerical models by LS-DYNA and UDEC have been used in this paper. The following conclusions can be drawn from the presented study.

Radial fractures have been created due to large tangential tensile stresses inside the pillar. Fractures parallel or subparallel to the surface of the tested panel have been generated by reflected radial tensile stress waves.

The responses of the tested panel and pillar are sensitive to the amount of explosives as well as the burden used. It seems that the use of a single blasthole may have been insufficient to test the support satisfactorily since it is affected by the creation of a cone-shaped area formed by radial fractures.

Based on the numeral back-analysis of simulated rockburst tests, an improved blast design was proposed for further tests. In order to obtain fractures caused by reflected tensile stress wave and reduce blasting induced radial fractures, 2 parallel blastholes are suggested with a larger burden (>5 m).

The coupled numerical technique has shown certain advantage in simulating blasting as well as stress wave-rock opening interaction, and the current numerical models have been used to explain the field tests with a certain level of success and have helped improve the blast design. If detailed geological structure and ground support system can be incorporated in the model and the model can be well calibrated, this could provide a tool for extrapolating results from simulated rockburst experiments. Further research will be conducted along this direction.

\section{Acknowledgement}

This work was financially supported by LKAB, Boliden, VINNOVA and Centre of Advanced Mining \& Metallurgy at LTU (CAMM) which are gratefully acknowledged. Language corrections by Mr Mikael Nilsson are greatly appreciated. The technicians and the mine surveyors in the LKAB Kiirunavaara mine are thanked for their consistent assistance in the field tests.

\section{References}

Andrieux, P., Turichshev, A., O'Connor, P. and Brummer, R.K. (2005) Dynamic testing with explosive charges of rockburst-resistant ground support systems at the Fraser Nickel Mine, Itasca Consulting Canada Inc Report to Falconbridge Limited Mine Technical Services; Final Version, September 2005, Sudbury, Canada, 102 p.

Archibald, J.F., Baidoe, J.P. and Katsabanis, P.T. (2004) Rockburst damage mitigation benefits deriving from use of spray-on rock linings, Surface Support in Mining, Y. Potvin, T.R. Stacey and J. Hadjigeorgiou (eds), Australian Centre for Geomechanics, Perth, pp. 169-178.

Borrvall, T. and Riedel, W. (2011) The RHT concrete model in LS-DYNA, in Proceedings Eighth European LS-DYNA users conference, 23-24 May, Strasbourg, France, $14 \mathrm{p}$.

Bouamoul, A. and Nguyen-Dang, T.V. (2008) High explosive simulation using arbitrary Lagrangian-Eulerian formulation, Technical Memorandum, Defence R\&D Canada, Valcartier, Canada, $34 \mathrm{p}$.

Brandshaug, T. (2009) An initial evaluation of the effects of seismic motion on a footwall drift at LKAB's Kiirunavaara mine, Internal Report, LKAB, Sweden, $36 \mathrm{p}$.

Dahner, C., Malmgren, L. and Bošković, M. (2012) Transition from non-seismic mine to a sesmically active mine: Kiirunavaara Mine, in Proceedings Eurock 2012, Befo (ed), 28-30 May 2012, Stockholm, Sweden, CD-Rom only.

Espley, S.J., Heilig, J. and Moreau, L.H. (2004) Assessment of the dynamic capacity of liners for possible application in highly stressed mining environments at Inco limited, Surface Support in Mining, Y. Potvin, T.R. Stacey and J. Hadjigeorgiou (eds), Australian Centre for Geomechanics, Perth, pp. 187-192.

Hadjigeorgiou, J. and Potvin, Y. (2007) Overview of dynamic testing of ground support, in Proceedings Fourth International Seminar on Deep and High Stress Mining (Deep Mining 07), Y. Potvin (ed), 7-9 November 2007, Perth, Australia, Australian Centre for Geomechanics, Perth, pp. 349-371.

Hagan, T.O., Milev, A.M., Spottiswoode, S.M., Hildyard, M.W., Grodner, M.A., Rorke, J., Finnie, G.J., Reddy, N., Haile, A.T., Le Bron, K.B. and Grave, D.M. (2001) Simulated rockburst experiment - an overview, The Journal of The South African Institute of Mining and Metallurgy, August 2001, pp. 217-222.

Hallquist, J. (2006) LS-DYNA theory manual, Livermore software technology corporation, Livermore, California, $680 \mathrm{p}$. 
Heal, D. and Potvin, Y. (2007) In-situ dynamic testing of ground support using simulated rockbursts, in Proceedings Fourth International Seminar on Deep and High Stress Mining (Deep Mining 07), Y. Potvin (ed), 7-9 November 2007, Perth, Australia, Australian Centre for Geomechanics, Perth, pp. 373-394.

Helte, A., Lundgren, J., Örnhed, H. and Norrefeldt, M. (2006) Prestandabestämning av svensk sprängdeg m/46, Rapport nr FOI-R2051-SE, FOI, Stockholm, Sweden.

Itasca Consulting Group (2011) UDEC-Universal Distinct Element Code, Version 4.01, User Manual, Minnesota, USA.

Kaiser, P.K., McCreath, D.R. and Tannant, D.D. (1996) Canadian rockburst support handbook, Geomechanics Research Centre, Sudbury, $300 \mathrm{p}$.

Malmgren, L. and Nordlund, E. (2008) Interaction of shotcrete with rock and rock bolts-A numerical study, International Journal of Rock Mechanics \& Mining Sciences, Vol. 45, pp. 538-553.

Malmgren, L. and Sjöberg, J. (2006) Bergmekaniska analyser för ny huvudnivå i KUJ (1365), Utredning nr 06-797, LKAB, Sweden.

Olsson, M., Nyberg, U. and Fjellborg, S. (2009) Kontrollerad sönderbrytning vid skivrassprängning - inledande försök, Swebrec report 2009:2, Swedish Blasting Research Centre, Stockholm, Sweden.

Ortlepp, W.D. (1992) Implosive-load testing of tunnel support, Rock Support in Mining and Underground Construction, Kaiser, P.K. and McCreath, D.R. (eds), Balkema, Rotterdam, pp. 675-682.

Riedel, W., Thoma, K., Hiermaier, S. and Schmolinske, E. (1999) Penetration of reinforced concrete by BETA-B-500, numerical analysis using a new macroscopic concrete model for hydrocodes, in Proceedings Ninth International Symposium on Interaction of the Effects of Munitions with Structures, SKA (ed), 3-7 May 1999, Berlin-Strausberg, Germany, pp. 315-322.

Schill, M. (2012) Finite element simulations of blasting and the effects of precise initiation on fragmentation, Swebrec report, Luleå University of Technology, Sweden.

Shirzadegan, S., Nordlund, E., Nyberg, U., Zhang, P., Malmgren, L. and Nordqvist, A. (2013) Rock support subjected to dynamic loading: field testing of ground support using simulated rockburst experiment, Research report, Luleå University of Technology, Sweden.

Stacey, T.R. (2012) A philosophical view on the testing of rock support for rockburst conditions, The Journal of The Southern African Institute of Mining and Metallurgy, Vol. 112, August 2012, pp. 703-710.

Tannant, D.D., Brummer, R.K. and Yi, X. (1995) Rockbolt behaviour under dynamic loading: field tests and modelling, International Journal of Rock Mechanics and Mining Sciences \& Geomechanics Abstracts, Vol. 32, pp. 537-550.

Zhang, P. and Yi, C.P. (2013) Coupled finite element and discrete element modeling of simulated rockburst tests at the Kiirunavaara underground mine, Research report, Luleå University of Technology, Sweden. 
Numerical back-analysis of simulated rockburst field tests by using coupled numerical

P. Zhang et al. technique 